\title{
A 2D SMOOTHED PARTICLE HYDRODYNAMICS THEORY FOR CALCULATING SLAMMING LOADS ON SHIP HULL SECTIONS
}

\author{
D J Veen and T P Gourlay, Centre for Marine Science and Technology, Curtin University, Australia
}

\section{SUMMARY}

Current methods for assessing slamming of ships in head seas are generally based on constant-velocity wedge impact results for each hull section. A 2D Smoothed Particle Hydrodynamics (SPH) method is described for calculating slamming loads on realistic hull section shapes and impact velocity profiles. SPH is a particle-based method that is mesh-free and is therefore able to accurately simulate large free surface deformations such as jets and splashes, which are an important factor in slamming events.

It is shown that large slamming pressures are predicted on wedge shaped hull sections and the concave part of flared monohull sections. Similarly, cross-deck slamming of catamaran hulls can produce large slamming pressures at the top of the arches. The nature of relative vertical velocity profiles during slam events is also discussed. Hull sections with varying velocity profiles are modelled using SPH to show the effect on slamming pressures as compared to the commonly used constant velocity profile.

\section{INTRODUCTION}

For a ship travelling into head seas, the relative motion between the bow and the water surface can cause the entire forward part of the hull to emerge from, and then crash back into the water surface. This phenomenon, known as "slamming", produces high localized pressures on the hull plating, as well as global loads on the ship. The problem may be particularly severe for high-speed vessels, due to the high wave encounter frequency and hence large relative vertical velocities.

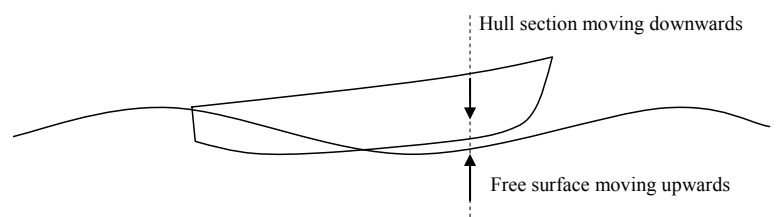

Figure 1: The relative motion between hull and water surface, leading to a slam event.

The idea of using the relative vertical motion to correlate with slamming pressures was used in the early model tests of Ochi [1] to analyse measured slamming loads. According to this method, the longitudinal slope of the keel is assumed small, so that the vertical water motion has the dominant effect on slamming pressures. Calculation of relative vertical motions, as the primary input for slamming assessment, has since become the method of choice in ship slamming studies.

Due to the slowly-varying shape of ship hulls in the longitudinal direction, slamming may also be modelled using a strip theory approach [2], in which the instantaneous free surface height at a given hull section is assumed largely independent of the neighbouring hull sections. Three-dimensional effects of the entire hull acting on the surface may be modelled by an empirical "swell-up coefficient" [2] obtained from model tests.
The strip theory approach allows the relative motion between each section and the water surface to be modelled using a two-dimensional formulation. In order to assess the slamming pressures on each hull section, the section is commonly modelled as a wedge of a given deadrise angle, impacting the water at a constant velocity $[2,3]$ (see Figure 2).

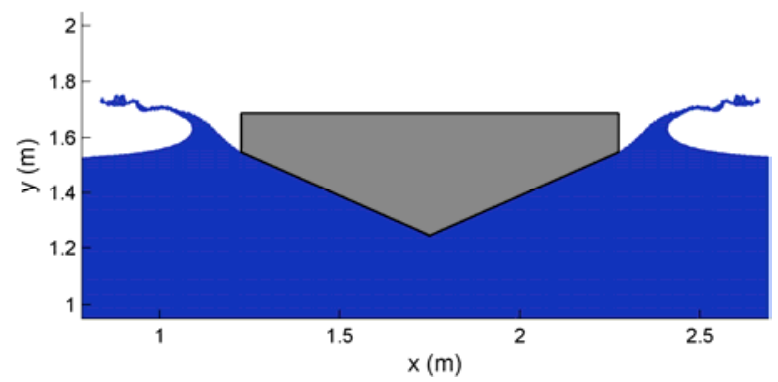

Figure 2: Example 2D flow about a slamming model hull section, viewed from ahead of the ship.

Reference is often made to model test results (e.g. [4]) for peak pressures on simple wedges at constant entry speed. These model test results have been found to agree well with the theoretical method described by Wagner [5]. In each case the local pressure maximum tracks along the wedge at approximately the vertical position of the still water level, keeping a near-constant value as it does so (see Figure 3). The magnitude of this maximum pressure is smaller for wedges with larger deadrise angle.

In this article, improvements are made to the constantvelocity wedge method for slamming assessment, using calculated results from Smoothed Particle Hydrodynamics [6]. SPH is a particle-based method that tracks the position, velocity and pressure of fluid elements using a Lagrangian formulation. As it has no mesh, it is able to model complicated free surface deformations such as jets and splashing. Accurate wall boundary conditions based on the ghost particle technique are used to determine slamming pressures. 


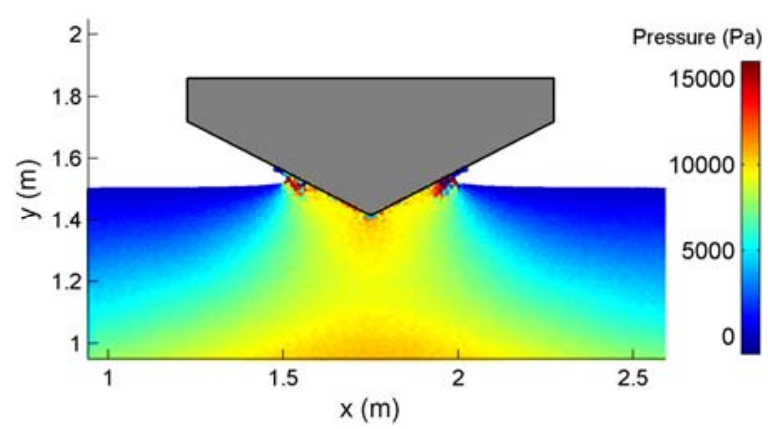

Figure 3: Instantaneous pressure distribution for a $30^{\circ}$ deadrise wedge model with a constant vertical velocity of $2.0 \mathrm{~m} / \mathrm{s}$.

\section{EFFECT OF HULL SECTION SHAPE}

Existing seakeeping software (e.g. [3]) typically approximates each hull section as an equivalent wedge and only calculates slamming pressures near the keel. The use of an SPH simulation allows slamming pressures to be determined over the entire section, which is particularly important in the case of flared hulls.

Measured slamming pressures [7] and observed damage [8] on vessels with significant bow flare has shown that particular areas of such hull sections may experience very high slamming pressures. Figure 4 describes the free surface impact, calculated using the SPH method, of the highly-flared hull section [9] described in Section 4. In this case, the initial impact speed is $0.6 \mathrm{~m} / \mathrm{s}$. The peak pressure reaches a value of $5.5 \mathrm{kPa}$ on the keel, $6.0 \mathrm{kPa}$ on the concave part of the section, and $5.5 \mathrm{kPa}$ just beneath the knuckle. So for flared hull sections it is insufficient to assume that the peak pressure occurs only at the keel, as done in many seakeeping methods.

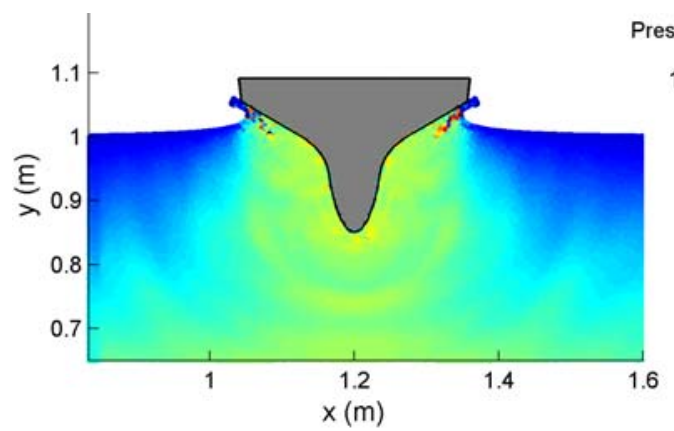

Pressure $(\mathrm{Pa})$ 10000 8000 6000 4000 2000

Figure 4: SPH pressure field surrounding the Aarsnes [9] freely-decelerating model test hull section

0.13 s after initial impact with the free surface.

Another hull form which requires special attention is the catamaran, where the cross-deck structure may impact the water surface (commonly termed wet-deck slamming). In this case, large slamming pressures may occur in the arches of the cross-deck structure [10], resulting in the hull experiencing significant loads. An example SPH pressure field of a 2D catamaran with a centre bow is illustrated in Figure 5.

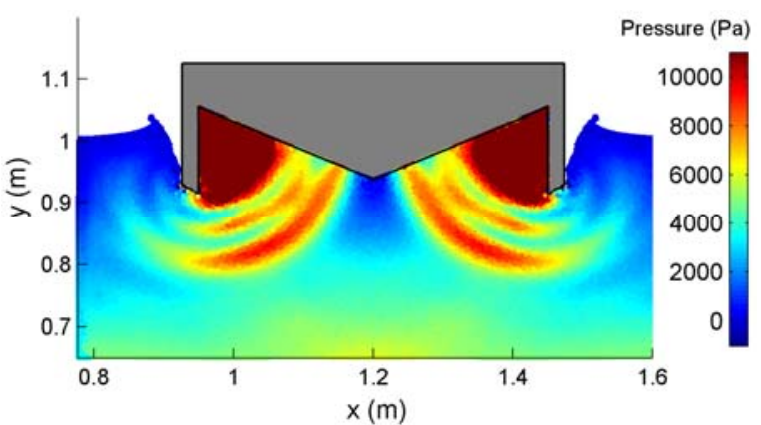

Figure 5: SPH pressure field surrounding

the Whelan [10] freely-decelerating catamaran model hull section $0.07 \mathrm{~s}$ after initial impact with the free surface at $1.0 \mathrm{~m} / \mathrm{s}$.

\section{EFFECT OF TIME-VARYING IMPACT VELOCITY}

In practice, bow impacts do not occur at constant relative vertical velocity. For minor slamming, the loads do not affect the overall heave and pitch of the vessel and the relative vertical velocity of the bow follows a nearsinusoidal motion $[11,12]$. For major slamming, an upward force is exerted on the bow which modifies the heave and pitch accordingly. Therefore, using the initial impact velocity as a constant vertical velocity to model slamming will cause over-estimation of the pressures above the keel, since in practice significant deceleration has occurred by the time these parts of the hull section hit the water (if at all).

The effect of time-varying impact velocity has been studied experimentally using drop tests [10]. Whelan [10] dropped freely a variety of model hull sections from differing heights above still water and recorded the loads and local pressure experienced. A 2D SPH model of the $15^{\circ}$ deadrise wedge studied in [10] was created with matching physical parameters, a beam of $0.5 \mathrm{~m}$ and a mass of $74 \mathrm{~kg}$. Three numerical pressure sensors were also placed in the same location as those used in [10] (see Figure 6).

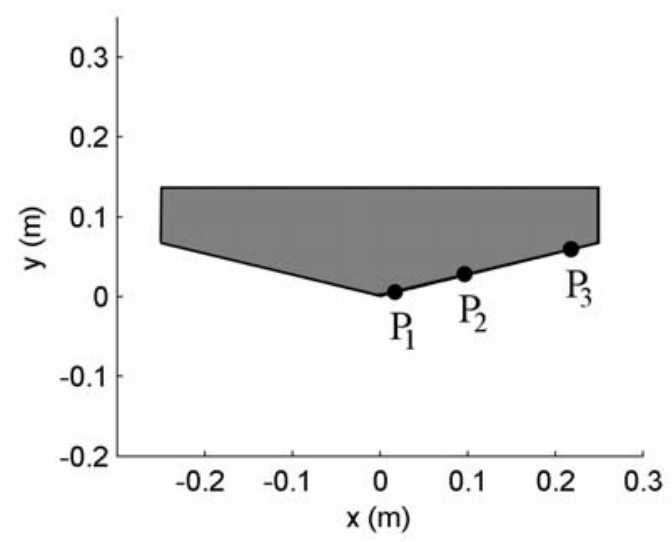

Figure 6: Diagram of the $15^{\circ}$ deadrise wedge studied in [10] including pressure sensors $\mathrm{P}_{1}, \mathrm{P}_{2}$ and $\mathrm{P}_{3}$. 

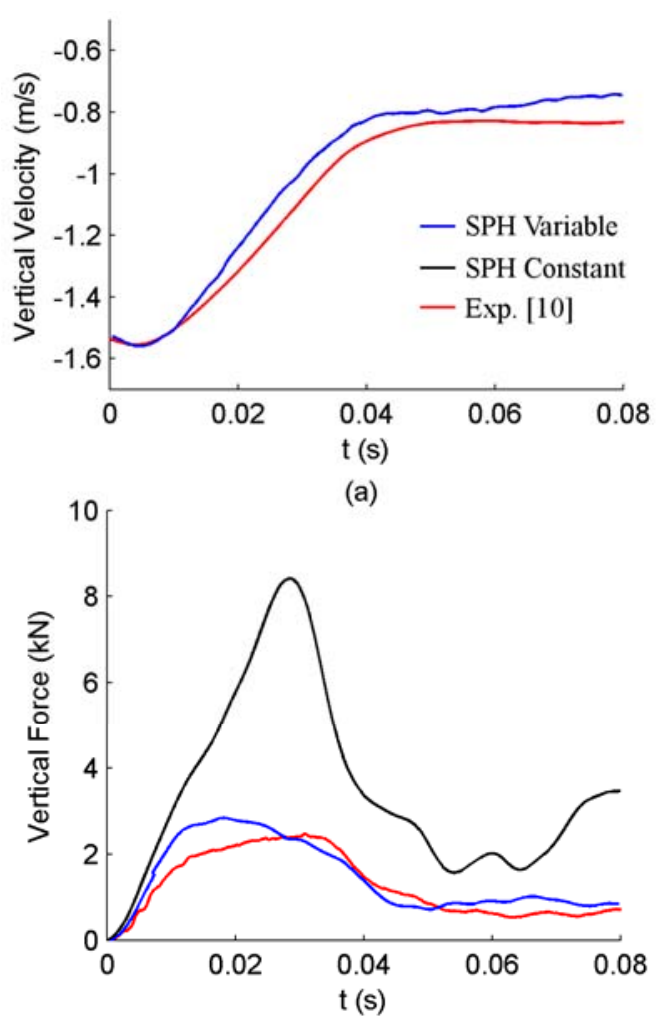

(b)
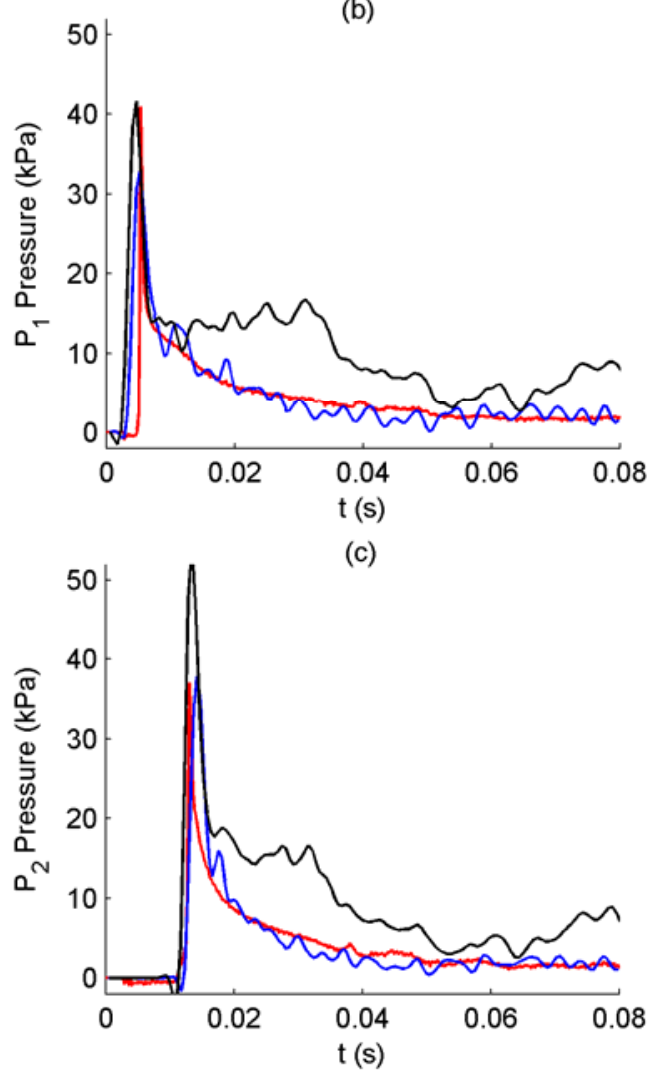

(d)

Figure 7: The vertical speed (a), force (b) and pressure at sensors $\mathrm{P}_{1}(\mathrm{c})$ and $\mathrm{P}_{2}(\mathrm{~d})$ for a $15^{\circ}$ deadrise wedge dropped from a height of $0.13 \mathrm{~m}$.
The vertical velocity profile for the simple case of a $15^{\circ}$ deadrise wedge dropped from a height of $0.13 \mathrm{~m}$ is described in Figure 7a. The vertical velocity of the simulated wedge initially follows that recorded during the experiment [10], but the SPH model does decelerate more rapidly after $0.1 \mathrm{~s}$. Without including air in the SPH model, compression effects near the free surface are ignored, resulting in a higher simulated force. This in turn is the cause of the more rapid SPH deceleration.

A second SPH simulation of the same wedge was also completed at a constant speed of $1.57 \mathrm{~m} / \mathrm{s}$, the initial entry speed of the experimental wedge. Comparing the peak vertical force in both simulations, the wedge in the constant velocity case was found to have approximately four times greater peak force than the variable-speed SPH case. Good agreement was found between the SPH and experimental results.

The larger vertical force recorded during the constant velocity SPH water entry is caused by differences in the fluid pressure, evident at sensors $\mathrm{P}_{1}$ and $\mathrm{P}_{2}$ (see Figures $7 \mathrm{c}$ and $7 \mathrm{~d}$ ). The pressure at $\mathrm{P}_{1}$ (Figure $7 \mathrm{c}$ ) is very similar for both SPH simulations, reaching a peak approximately $0.005 \mathrm{~s}$ after the vertex strikes the water surface. However, by the time the peak pressure is experienced at $\mathrm{P}_{2}$ (Figure $7 \mathrm{~d}$ ), approximately $0.013 \mathrm{~s}$ after the vertex strikes the water surface, the variable entry speed wedge has decelerated (Figure 7) and the resulting pressure is much smaller than the constant speed SPH simulation. Furthermore the constant velocity SPH pressure recorded at both sensors after the initial peak remains considerably higher than both the variable entry speed SPH wedge and experimental wedge, further increasing the measured vertical force.

In summary, by comparing the experimental and SPH variable entry speed results, it can be seen that the SPH model is able to accurately simulate the pressures and net vertical force on a wedge during water entry.

\section{FLARED HULL WITH TIME-VARYING IMPACT VELOCITY}

Aarsnes [9] performed drop tests on a model flared hull bow section and measured the total load, slamming pressures and deceleration profile. The hull section and the location of the four pressure sensors are illustrated in Figure 8 . The length and beam of the model were $1.0 \mathrm{~m}$ and $0.32 \mathrm{~m}$ respectively, while the mass of the falling rig was $261 \mathrm{~kg}$.

The drop test impact was modelled using the SPH methods described in [6], with a resolution of 400 particles per metre. The curved hull was approximated by a series of straight-line segments (see Figure 8), and the ghost particle method (see [6]) used to provide the wall boundary condition. The model was allowed to dynamically respond to the calculated vertical hydrodynamic force. 


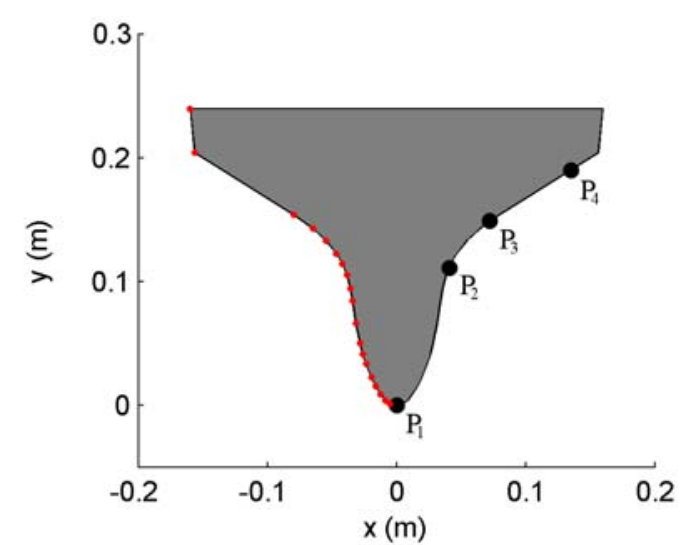

Figure 8: The flared hull section drop tested by Aarsnes [9]. The location of pressure sensors $P_{1}-P_{4}$ is illustrated on the right-hand side and the straight-line segment vertices for SPH modelling are shown on the left.

The vertical velocity, force and pressure at sensors $\mathrm{P}_{2}$ and $\mathrm{P}_{3}$, measured when the hull section was dropped (freely in the vertical direction) from a height of $0.32 \mathrm{~m}$, are illustrated in Figure 9. The measured [9] and simulated (SPH) vertical forces agree well, however there is some difference in the vertical speed profile. One possible cause of this difference is friction in the falling rig (not accounted for in the vertical force measurements) decreasing the vertical speed.

The higher SPH impact velocity is evident in the pressure recorded at sensors $\mathrm{P}_{2}$ and $\mathrm{P}_{3}$. The $\mathrm{SPH}$ peaks occur sooner and have a slightly higher magnitude than those recorded by Aarsnes [9].

From the results obtained it is clear that the SPH method is able to model the dynamic problem of slamming pressures on a decelerating object with reasonable accuracy.

\section{RELATIVE VERTICAL VELOCITY PROFILES}

The drop test experiments described above illustrate the effect of varying vertical velocity, but are not quite representative of the real impact velocity profile of a ship in a seaway. In that case, each hull section is constrained by its connection to adjacent hull sections, and the motions must be calculated for the ship as a whole. For minor slamming, the relative vertical velocity follows a sinusoidal pattern $[11,12]$, which can be calculated independently of the slamming loads [2]. For major slamming, the loads must be calculated and fed back into the seakeeping analysis.

Calculating the overall slamming motions of a ship, by combining seakeeping and 2D SPH analysis, is a topic of ongoing research which is due to be published shortly by the authors.
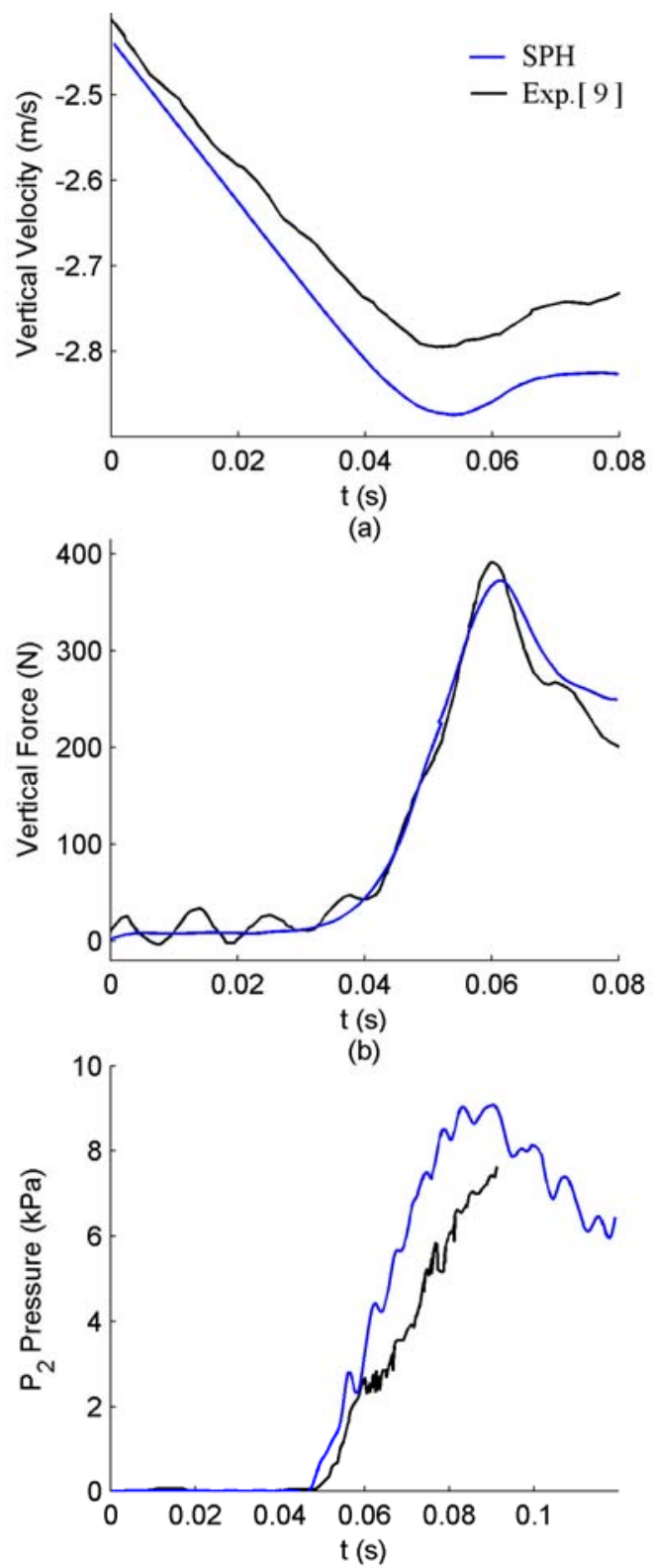

(c)

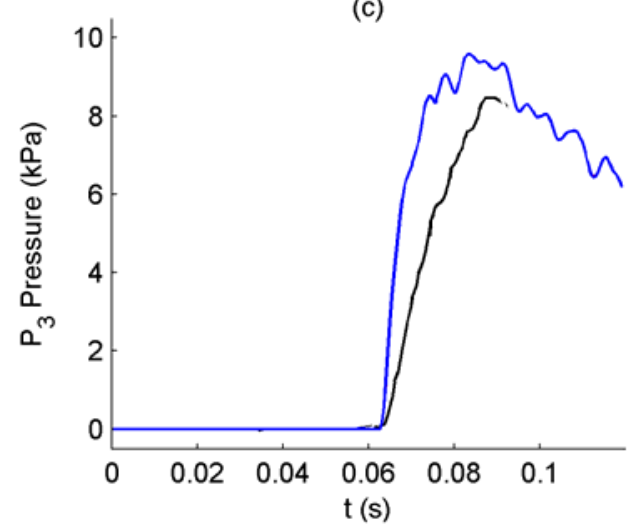

(d)

Figure 9: The vertical speed (a), force (b) and pressure at sensors $\mathrm{P}_{2}(\mathrm{c})$ and $\mathrm{P}_{3}(\mathrm{~d})$ for the Aarsnes

[9] hull section dropped from a height of $0.31 \mathrm{~m}$. 


\section{CONCLUSIONS}

For minor slamming impacts of wedge-shaped hull sections, where the only point of interest is the keel, existing strip theory methods based on constant-velocity wedge impacts are appropriate. However, in order to model slamming pressures higher up the hull (such as near the knuckle of flared sections) alternative methods are needed. Such methods must account for the changing shape of the hull, as well as the varying impact velocity as the hull enters the water.

For major slamming impacts, even of wedge-shaped sections, the slamming loads affect the global heave and pitch motions, and need to be calculated over the entire hull section rather than just at the keel.

Smoothed Particle Hydrodynamics (SPH) has been put forward in this article as an appropriate solution to these deficiencies. It is able to model a wide range of straight or curved sectional shapes, through use of a ghost particle wall boundary condition. As a mesh-free method, $\mathrm{SPH}$ can model the jets and splashing which are important features of slam events. SPH is also able to cope with any prescribed velocity profile, or alternatively calculate vertical forces to modify the velocity profile as required.

\section{REFERENCES}

[1] OCHI, M.K., Model experiments on ship strength and slamming in regular waves, Transactions of the Royal Society of Naval Architects and Marine Engineers 66: 345-383, 1958.

[2] LLOYD, A.R.J.M., 'Seakeeping: Ship Behaviour in Rough Weather’, Ellis Horwood, 1989.

[3] JOURNEE, J.M.J, ADEGEEST, L.J.M., Theoretical Manual of Strip Theory Program "Seaway for Windows", TU Delft Report 1370, 2003.

[4] HAGIWARA, K., YUHARA, T., Study of wave impact load on ship bow, Japan Shipbuilding and Marine Engineering, Vol. 8, No. 4, 1974.

[5] WAGNER, H., The phenomena of impacts and sliding on liquid surfaces. NACA translation 1366, National Advisory Committee for Aeronautics, Washington, 1932.

[6] VEEN, D.J., A Smoothed Particle Hydrodynamics Study of Ship Bow Slamming in Ocean Waves, Ph.D. thesis, Centre for Marine Science and Technology, Curtin University.

[7] VULOVICH, R., HIRAYAMA, T., TOKI, N., MIZUNO, H., Characteristics of hull stresses measured on a large containership in rough seas. Transactions of the Society of Naval Architects and Marine Engineers 97: 397-428, 1989.

[8] YAMAMOTO, Y., IIDA, K., FUKUSAWA, T., MURAKAMI, T., ARAI, M., ANDO, A., Structural damage analysis of a fast ship due to bow flare slamming. International Shipbuilding Progress 32 (369): 124-136, 1985

[9] AARSNES, J.V., Drop test with ship sections - effect of roll angle, Report No. 603834.00.01, Norwegian Marine Technology Research Institute, Trondheim, Norway, 1996.

[10] WHELAN, J.R., Wetdeck slamming of high-speed catamarans with a centre bow, Ph.D. Thesis, School of Engineering, University of Tasmania, Hobart, 2004.

[11] HERMUNDSTAD, O.A., MOAN, T., Numerical and experimental analysis of bow flare slamming on a Ro-Ro vessel in regular oblique waves. Journal of Marine Science and Technology 10: 105-122, 2005.

[12] SEBASTIANI, L., VALDENAZZI, F., GROSSI, L., KAPSENBERG, G.K., A theoretical/experimental investigation of the slamming pressures on fast monohull vessels. In Proceedings of the 6th International Conference on Fast Sea Transportation, Southampton, UK, 2001.

\section{AUTHORS' BIOGRAPHY}

Daniel Veen has recently submitted his Ph.D. thesis at the Centre for Marine Science and Technology (CMST), Curtin University. He has developed a Smoothed Particle Hydrodynamics code from first principles, and is now using it to model complex free surface problems such as ship slamming.

Tim Gourlay is a Senior Research Fellow in ship hydrodynamics at CMST. He has supervised Daniel Veen's Ph.D. thesis and is continuing research on the topic of SPH. 